\title{
RESPOSTA DE Acacia mangium Willd A INOCULAÇÕES COM RIZÓBIO E MICORRIZA EM DIFERENTES NÍVEIS DE FÓSFORO EM SOLO DE RESTINGA DEGRADADO
}

\author{
S. L. R. TAVARES ${ }^{*}$, A. A. FRANCO ${ }^{2}$ e E.M.R. SILVA ${ }^{2}$ \\ ${ }^{1}$ Empresa Brasileira de Pesquisa Agropecuária (EMBRAPA SOLOS) \\ ${ }^{2}$ Empresa Brasileira de Pesquisa Agropecuária (EMBRAPA AGROBIOLOGIA) \\ silvio.tavares@embrapa.br*
}

Artigo submetido em dezembro/2015 e aceito em setembro/2016

DOI: $10.15628 /$ holos.2016.3932

\begin{abstract}
RESUMO
Para avaliar os efeitos da inoculação com Bradyrhizobium, fungos micorrízicos arbusculares (FMA) e níveis de fósforo em mudas de Acacia mangium Willd, plantadas em um solo espodossolo humilúvico de restinga degradada, adubado com cinco níveis de fósforo e duas fontes fosfatadas, no crescimento, nodulação, colonização micorrízica e teores e acúmulos de macro e micronutrientes, foi realizado um experimento em vasos plásticos, utilizando um delineamento experimental inteiramente casualizado, em esquema fatorial completo $2 \times 4 \times 5$ com 4 repetições. Os tratamentos foram: duas fontes de fósforo (fosfato de rocha e super triplo); quatro tratamentos microbiológicos (testemunha não inoculada; rizóbio; micorriza; e rizóbio + micorriza); e cinco níveis de
\end{abstract}

fósforo (0; 15; 30; 60 e $\left.120 \mathrm{mg} \cdot \mathrm{kg}^{-1}\right)$. Avaliaram-se as mudas aos 59 dias após o plantio. As mudas colonizadas apresentaram, em média, aumentos significativos em relação as não colonizadas, na maioria dos parâmetros estudados. Foram observadas em alguns parâmetros (principalmente os de crescimento), diferenças estatísticas entre fontes de fósforo. As doses de fósforo também influenciaram de maneira positiva incrementos em muitos parâmetros analisados. Os resultados mostram a importância da associação de plantas fixadoras de nitrogênio com FMA, juntamente com o fornecimento de fósforo no processo de recuperação de solos arenosos em restinga degradada.

PALAVRAS-CHAVE: Mudas florestais, FBN, simbiose, RAD, nutrição vegetal.

\section{Acacia mangium Willd OF RESPONSE TO INOCULATIONS WITH RHIZOBIUM AND MYCORRHIZA AT DIFFERENT LEVELS IN RESTIGA DEGRADED SOIL}

\begin{abstract}
To evaluate the effects of inoculation with Bradyrhizobium, mycorrhizal fungi and phosphorus levels in Acacia mangium Willd seedlings, planted in a soil Spodosol degraded sandbank, fertilized with five levels of phosphorus and two phosphate sources, in growth, nodulation, mycorrhizal colonization and content and accumulation of macro and micronutrients, an experiment was conducted in plastic pots, using a completely randomized design, full factorial $2 \times 4 \times 5$ with 4 repetitions. The treatments were: two sources of phosphorus (phosphate rock and super triple); four microbiological treatments (non-inoculated control;
\end{abstract}

rhizobia; mycorrhiza; rhizobia and mycorrhizal); and five phosphorus levels $(0,15,30,60$ and 120 mg.kg-1). We evaluated the seedlings to 59 days after planting. The colonized seedlings showed, on average, significant increases over the unsettled in most parameters studied. They were observed in some parameters statistical differences between phosphorus sources. Phosphorus levels have also influenced positively increments in many parameters analyzed. The results show the importance of the association of nitrogen fixing plants with fungis, together with the phosphorus supply in sandy soils recovery process in degraded.

KEYWORDS: : Grow seedlings, biological nitrogen fixation, symbiosis, recovery of degraded area, plant nutrition. 


\section{INTRODUÇÃO}

De uma maneira geral, os solos brasileiros, especialmente os degradados, são deficientes em fósforo para as culturas agrícolas e/ou florestais, fazendo com que os fertilizantes fosfatados tenham um papel importante no sistema de recuperação desses solos.

Além da deficiência quase que generalizada de fósforo nos solos tropicais, vários fatores agravam ainda mais a sua disponibilidade para as plantas. Entre esses fatores, podemos destacar a elevada capacidade de adsorção de fósforo nos solos geneticamente antigos; elevada acidez associada a alta saturação de alumínio e baixa disponibilidade de nutrientes que refletem de maneira direta nas limitações deste macronutriente nestes solos.

No Brasil, quantidades relativamente elevadas de fertilizantes fosfatados são requeridas para o cultivo nestes solos, e conjuntamente com as altas taxas de fixação e imobilização de fósforo por estes solos, aliados aos altos preços dos fertilizantes industrializados que são importados, leva a comunidade científica a dar ênfase aos estudos das associações de plantas com microrganismos que favoreçam um maior aproveitamento deste nutriente na agricultura.

Os fungos micorrízicos de ocorrência generalizada tem sido amplamente estudados, principalmente no que se refere ao aumento da aquisição de fósforo. A maior absorção de fósforo pelas plantas micorrizadas tem sido atribuída à exploração de maior volume de solo e a maior capacidade das hifas extra radicais do fungo em absorver $\mathrm{P}$ em baixa concentração, permitindo a sua absorção além da zona de esgotamento que se desenvolve ao redor das raízes.

A utilização de leguminosas em Programas de Recuperação de Áreas Degradadas (PRAD) é de considerável importância, devido a capacidade destas em fixar o $\mathrm{N}_{2}$ atmosférico em simbiose com bactérias do gênero Rhizobium, o que possibilita a manutenção de níveis adequados de nitrogênio no solo para o crescimento vegetal, dispensando o uso de fertilizantes nitrogenados, que além de caros, podem exercer impactos sobre os ecossistemas. Além dessas bactérias, fungos micorrízicos devem serem adicionados aos pacotes biotecnológicos visando baratear a tecnologia e aumentar a eficiência desses e outros nutrientes no sistema solo-planta.

O presente trabalho tem como objetivo avaliar a resposta da Acacia mangium Willd à doses de fósforo, inoculações com fungos micorrízicos e rizóbios em um solo de restinga degradado da Região dos Lagos (Saquarema, RJ) utilizando diferentes fontes e doses de fósforo.

\section{METODOLOGIA}

O presente estudo constou de um experimento conduzido em vasos plásticos com capacidade de 10 litros mantidos à descoberto no campus da Embrapa Agrobiologia, no município de Seropédica, RJ, localizado a $22^{\circ} 46^{\prime}$ de latitude sul e $43^{\circ} 41^{\prime}$ de longitude oeste, com altitude de 33 metros.

O substrato utilizado foi proveniente de um solo classificado como Espodossolo, coletado num ecossistema de restinga a uma profundidade de $0-20 \mathrm{~cm}$ na área de preservação ambiental de Jacarapiá, no município de Saquarema, RJ, passado em peneira de $5 \mathrm{~mm}$, apresentando as seguintes características físicas e químicas: $\mathrm{pH}$ em água $(1: 2,5)=5,1 ; \mathrm{N}=12 \mathrm{~g} \cdot \mathrm{dm}^{-3} ; \mathrm{P}=1 \mathrm{mg} \cdot \mathrm{dm}^{-3}$; $\mathrm{K}=0,5 \mathrm{mmol}_{\mathrm{c}} \cdot \mathrm{dm}^{-3} ; \mathrm{Ca}^{2+}+\mathrm{Mg}^{2+}=7 \mathrm{mmol}_{\mathrm{c}} \cdot \mathrm{dm}^{-3} ; \mathrm{Al}^{3+}=0 \mathrm{mmol}_{\mathrm{c}} \cdot \mathrm{dm}^{-3} ; \mathrm{H}^{+}+\mathrm{Al}^{3+}=5 \mathrm{mmol}_{\mathrm{c}} \cdot \mathrm{dm}^{-3} ; \mathrm{Na}$ 
$=0,26 \mathrm{mmol}_{\mathrm{c}} \cdot \mathrm{dm}^{-3} ; \mathrm{C}=2,4 \mathrm{~g} \cdot \mathrm{dm}^{-3} ;$ M.O. $=5,0 \mathrm{~g} \cdot \mathrm{dm}^{-3} ;$ soma de bases $(\mathrm{S})=5 \mathrm{mmol}_{\mathrm{c}} \cdot \mathrm{dm}^{-3} ; \mathrm{CTC}=16$ mmol. $\mathrm{dm}^{-3}$; saturação de bases $(V)=29,0 \%$; areia grossa $=950 \mathrm{~g} \cdot \mathrm{dm}^{-3}$; areia fina $=10 \mathrm{~g} \cdot \mathrm{dm}^{-3}$; silte $=20 \mathrm{~g} \cdot \mathrm{dm}^{-3}$; argila $=20 \mathrm{~g} \cdot \mathrm{dm}^{-3}$ de solo. As densidades real e aparente, em $\mathrm{g} . \mathrm{cm}^{-3}$ foram respectivamente: 2,63 e 1,72. A porosidade total determinada e calculada em $\%$ foram respectivamente: 40 e 35 . A macroporosidade determinada e calculada em $\%$ foram 35 e 30 e a microporosidade $(\%)=5$. A condutividade hidráulica foi superior a $25 \mathrm{~cm} / \mathrm{h}$ (classe de permeabilidade $=$ muito rápida). Esses resultados foram obtidos conforme metodologias descritas pela Empresa Brasileira de Pesquisa Agropecuária, 1979.

Tabela 1: Análise química do substrato utilizado para a produção de mudas e do solo de restinga natural adubado com os diferentes níveis de fósforo e de fontes de fertilizantes fosfatados:

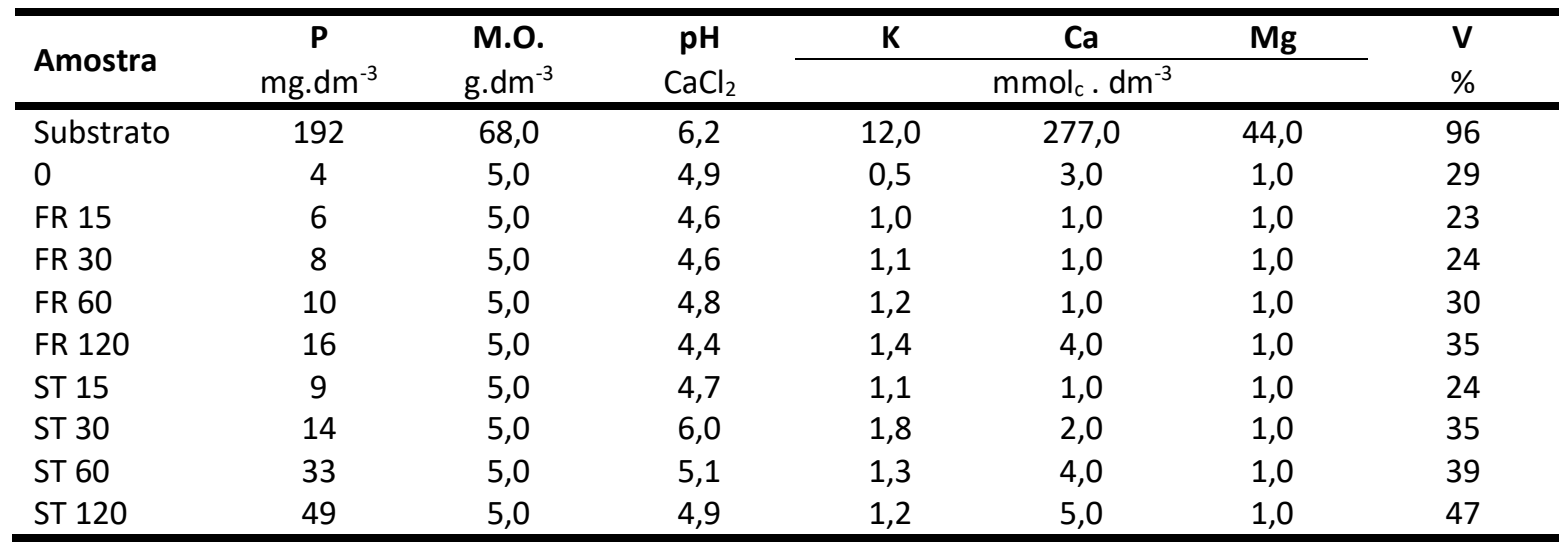

As análises mineralógicas na fração terra fina, realizadas no laboratório de mineralogia da Embrapa Solos, revelaram a presença de quartzo em percentual extremamente dominante de superfície fosca, subarredondados, arredondados e bem arredondados; presença de mineral opaco ilmenita e rutilo (alguns apresentando alterações); traços de turmalina, rutilo (transparente), zicão, mica alterada, leucoxênio e feldspato.

No substrato em questão, foi realizada uma avaliação da densidade de esporos de fungos micorrízicos nativos, após a separação de esporos por peneiramento úmido (GERDEMANN \& NICOLSON, 1963) e centrifugação e flutuação em sacarose (JENKINS, 1974). Após a recuperação dos esporos no solo, a quantificação foi efetuada com o auxílio de um microscópio estereoscópio, que revelou uma média de 580 esporos por $50 \mathrm{ml}$ de solo. Os esporos foram contados e montados em lâminas para caracterização. Os tipos mais encontrados foram identificados em nível de gênero e o predominante, em nível de espécie. Esses esporos de fungos micorrízicos nativos foram coletados em 40 pontos diversos aleatórios da área deste solo de restinga sob clareiras (sem vegetação arbórea, mas apresentando vegetação rasteira composta basicamente por Paspalum maritimum ou em área sem nenhuma vegetação), nas camadas de 0 a $40 \mathrm{~cm}$ de profundidade formando assim 4 amostras compostas oriundas de 40 amostras simples. 0 número de esporos citados anteriormente, representa uma média dessas repetições. Os fungos encontrados foram Acaulospora sp, Glomus macrocarpum e Glomus etunicatum.

O experimento foi conduzido em delineamento inteiramente casualizado com os tratamentos dispostos em esquema fatorial completo $2 \times 5 \times 4$ com 4 repetições, formados por duas fontes de adubos fosfatados (fosfato de rocha e supertriplo) X 5 níveis de adubação (0; 15; 30; 60 e $120 \mathrm{mg}$ de $\mathrm{P}$ por quilo de solo) e os 4 tratamentos microbiológicos: Testemunha sem inoculação (Test.), Inoculado com bradyrhizobium (R); Inoculado com fungo micorrízico arbuscular (M); Inoculado com bradyrhizobium e fungo micorrízico arbuscular ( $\mathrm{R}+\mathrm{M})$. Foram utilizados mudas 
produzidas em substrato contendo em volume: $30 \%$ de areia; $30 \%$ de argila; $30 \%$ de comporto orgânico e $10 \%$ de fosfato de rocha. As mudas foram transplantadas para os vasos experimentais aos 125 dias após semeadas e mantidas em casa-de-vegetação em ambiente com condições climáticas controladas.

Devido o substrato apresentar baixos níveis dos nutrientes essenciais à produção vegetal, foi realizada uma adubação inicial nos vasos de modo a não comprometer as observações experimentais e se aproximar das condições de plantio reais de campo. Foi feita uma adubação potássica de 0,48 g de $\mathrm{K}_{2} \mathrm{SO}_{4} / \mathrm{vaso}$, que corresponde a $48 \mathrm{~kg}$ de $\mathrm{K}_{2} \mathrm{O} / \mathrm{ha}$ (nível recomendado por FREIRE \& ALMEIDA (1988) para plantio de espécies florestais para o Estado do Rio de Janeiro), visando o suprimento de $\mathrm{K}$ e $\mathrm{S}$ e uma adubação de $2,5 \mathrm{~g}$ por vaso de FTE BR 12 , como fonte de micronutrientes, além da adubação fosfática com as duas fontes e os quatro níveis de adição de de fósforo. Foram realizadas também duas adubações de manutenção com $3,7 \mathrm{~g}$ de $\mathrm{CaCl}_{2} \cdot 2 \mathrm{H}_{2} \mathrm{O}$; 4,3 g de $\mathrm{CaSO}_{4} .2 \mathrm{H}_{2} \mathrm{O} ; 2,5 \mathrm{~g}$ de $\mathrm{MgSO}_{4} .7 \mathrm{H}_{2} \mathrm{O}$ e $0,48 \mathrm{~g}$ de $\mathrm{K}_{2} \mathrm{SO}_{4}$ (todos os sais utilizados foram da marca MERK p.a.), aos 20 e 40 dias após o transplantio de cada espécie para os vasos.

A Acacia mangium foi colhida aos 59 dias após o transplantio. Os parâmetros avaliados foram altura, massa seca da parte aérea e das raízes, diâmetro à altura do colo, número e peso dos nódulos secos, porcentagem de colonização pelas MVAs (PHILLIPS \& HAYMAN (1970), adaptados por ABBOTT \& ROBSON (1981) e concentração de N, P, K, Ca, Mg, S, Cu, Mn, Fe e Zn (Manual de Métodos de Análises de Solos da Embrapa Solos).

Os parâmetros estudados foram submetidos às análises de variância e teste de médias, utilizando-se o Sistema de Análises Estatísticas e Genéticas (SAEG), desenvolvido pelo setor de processamento de dados da Universidade Federal de Viçosa (UFV). Todos os parâmetros estudados foram submetidos, antes das análises estatísticas paramétricas usuais, ao teste de Lillieforms (que é uma derivação do teste de Kolmogorov-Smirnov), para verificar se os valores de dados de uma determinada variável seguem ou não uma distribuição de médias e desvios-padrão calculados na mesma amostra (se eles têm distribuições normais). Os dados também foram submetidos ao teste de Cochran que é usado para a verificação da homogeneidade de variâncias. Estes testes visam viabilizar a aplicação das análises de variância, que só poderá ser aplicada a um conjunto de observações se estiverem satisfeitas as pressuposições de independência, normalidade e variância constante (VIEIRA \& HOFFMANN, 1989).

Alguns parâmetros reprovados nos testes tiveram seus valores transformados e em seguida foram novamente submetido aos mesmos testes, até se chegar a uma transformação de dados aceita e aprovada pelo modelo matemático. Só a partir destes testes preliminares é que as variáveis em estudo foram submetidas aos testes de significância, testes de médias e análises de regressão.

As análises de regressões, foram calculadas em todas as aproximações e desmembramentos efetuados nas tabelas de ANOVAF, utilizando o procedimento REGRELIN do SAEG, por ser o mais recomendado quando, na análise de variância, existem fontes de variação do tipo nível ou suas classes não são independentes entre si e não são também equidistantes (MONTGOMERY \& PECK, 1982). Foi utilizado em todas as análises estatísticas o programa SAEG. Os dados referentes ao número de nódulos e colonização micorrízica foram transformados por $\sqrt{ } \mathrm{x}+1$ e arco seno $\mathrm{V} \mathrm{x} / 100$, respectivamente. 


\section{RESULTADOS E DISCUSSÕES}

\subsection{Influência das fontes de fósforo e tratamentos microbiológicos}

Os efeitos das duas fontes de fósforo e dos diversos tratamentos microbiológicos nos parâmetros de crescimento, nodulação e colonização micorrízica, encontram-se na tabela 2 . Verifica-se que não houve efeito significativo de fontes nos parâmetros: diâmetro à altura do colo (D), número de nódulos (NN) e colonização micorrízica (COLMIC). No restante dos parâmetros de crescimento houve superioridade, em média, quando se utilizou o superfosfato triplo como fonte de $P$. Com exceção da relação massa seca das raízes/massa seca da parte aérea (MSR/MSPA), todos os parâmetros foram afetados pelos tratamentos microbiológicos, tendo uma superioridade similar quando os vegetais foram submetidos a inoculações com rizóbio isoladamente ou com dupla inoculação (rizóbio e micorriza). Não houve diferença estatística nesses parâmetros com relação aos outros dois tratamentos microbiológicos (testemunha e inoculação isolada com micorriza), que se mostraram sempre inferiores aos tratamentos com os outros simbiontes.

Os teores de nutrientes que foram afetados pelas fontes de fósforo foram: $\mathrm{P}, \mathrm{Ca}$ e $\mathrm{Mn}$ (tabelas 3 e 4). Todos os nutrientes acumulados na matéria seca da parte aérea foram influenciados pelas fontes de $\mathrm{P}$, a exceção do cobre acumulado. Em todos os nutrientes acumulados e nos teores que foram significativos a nível de $5 \%$ de probabilidade pelo teste $\mathrm{F}$, quando se usou o superfosfato triplo como fonte de $\mathrm{P}$ foram superiores em relação ao fosfato de rocha.

Não houve interação significativa (fonte $x$ tratamentos microbiológicos) nos parâmetros de crescimento, nodulação e colonização micorrízica, ao passo que houve interação nos parâmetros nutricionais: cálcio acumulado (CaT), manganês acumulado (MnT), ferro acumulado (FeT) e zinco acumulado (ZnT).

O superfosfato triplo como fonte fornecedora de P no sistema, mostrou-se mais eficiente do que o fosfato de rocha, devido principalmente a uma maior disponibilidade de fósforo no solo (tabela 1), já que o maior nível adicionado de fosfato de rocha $\left(120 \mathrm{mg} \cdot \mathrm{kg}^{-1}\right)$ correspondeu praticamente ao nível de $30 \mathrm{mg} \cdot \mathrm{kg}^{-1}$ do supertriplo, quando recuperado pelo extrator resina. Este mesmo resultado foi observado (tabelas 3 e 4) onde os teores e acúmulos de $P$ na parte aérea foram maiores para as plantas adubadas com o superfosfato triplo em detrimento daquelas adubadas com fosfato natural. O percentual em média de $43 \%$ de $\mathrm{P}_{2} \mathrm{O}_{5}$ total solúvel em citrato neutro de amônio do supertriplo, contra apenas $5 \%$ em média do fosfato natural, no "período de incubação" de 59 dias de reatividade no solo arenoso de restinga, não permitiu uma maior expressão do efeito mais residual do fosfato natural neste tipo de solo ao longo do tempo. Logo, nas condições experimentais analisadas, a eficiência agronômica do supertriplo, ou seja, sua capacidade de provocar o maior acréscimo de rendimento (no caso acumulações nos solos e nas plantas) por unidade de fósforo aplicada (GOEDERIT \& SOUZA, 1984), foi maior do que o fosfato natural. 
Tabela 2: Médias e testes de médias dos parâmetros de crescimento, nodulação e colonização micorrízica

observadas em mudas de Acacia mangium Willd, submetidas à inoculações com Bradyhizobium e fungos micorrízicos arbusculares, em diferentes fontes e níveis de fósforo, aos $\mathbf{5 9}$ dias após o transplantio para vasos com solo de restinga (média de 4 repetições - valores por planta):

Diâmetro à Altura do Colo - D (mm)

Massa Seca da Parte Aérea- MSPA(g.pl $\left.{ }^{-1}\right)$

Massa Seca das Raízes - MSR (g.pl-1)

Massa dos Nódulos Secos-MNS (mg. $\left.\mathrm{pl}^{-1}\right)^{(2)}$

TM ${ }^{(1)} \quad$ Níveis de $\mathrm{P}$ ( $\mathrm{mg} \mathrm{P} \mathrm{Kg}^{-1}$ de solo)

Altura - H (cm)

FR

FR

ST

$\begin{array}{cccccccc}\text { Test. } & 22,7 & 23,4 & 24,2 & 26,8 & 25,9 & 24,62 & \text { b } \\ \text { R } & 35,8 & 36,9 & 38,7 & 39,7 & 41,4 & 38,57 & \text { a } \\ \text { M } & 24,8 & 24,2 & 25,0 & 24,8 & 26,9 & 25,15 & \text { b } \\ \text { R + M } & 36,6 & 37,1 & 38,6 & 39,6 & 40,9 & 38,76 & \text { a }\end{array}$

$\begin{array}{llllllll}\text { Média } & 29,9 & 30,4 & 31,6 & 32,8 & 33,8 & 31,73 & \text { B }\end{array}$

$\begin{array}{lllllll}R & 36,7 & 39,1 & 39,8 & 42,8 & 43,5 & 40,37\end{array}$

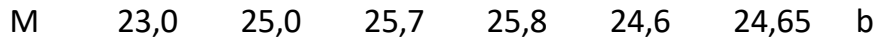

$\begin{array}{lllllll}R+M & 35,2 & 38,7 & 40,5 & 44,1 & 45,9 & 40,88\end{array}$

\begin{tabular}{cccccccc} 
Média & 29,9 & 32,4 & 33,7 & 34,8 & 35,2 & 32,25 & $\mathrm{~A}$ \\
\hline Test. & 3,27 & 3,30 & 3,36 & 3,44 & 3,45 & 3,36 & $b$
\end{tabular}

$\begin{array}{llllllll}R & 3,80 & 4,24 & 4,40 & 4,56 & 4,64 & 4,33 & \text { a }\end{array}$

$\begin{array}{lllllll}M & 3,24 & 3,27 & 3,30 & 3,46 & 3,41 & 3,34\end{array}$

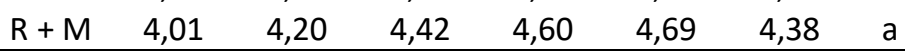

\begin{tabular}{|c|c|c|c|c|c|c|}
\hline Média & 3,58 & 3,75 & 3,87 & 4,01 & 4,05 & 3,84 \\
\hline
\end{tabular}

$\begin{array}{llllllll}\mathrm{R} & 4,10 & 4,27 & 4,51 & 4,78 & 4,84 & 4,50 & \text { a }\end{array}$

$\begin{array}{lllllll}M & 3,26 & 3,30 & 3,37 & 3,41 & 3,31 & 3,33\end{array}$

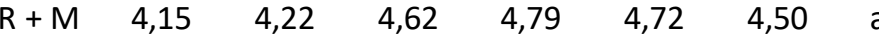

\begin{tabular}{cccccccc} 
Média & 3,70 & 3,77 & 4,05 & 4,18 & 4,08 & 3,95 & \\
\hline Test. & 2,36 & 2,64 & 2,37 & 2,41 & 2,31 & 2,42 & $b$
\end{tabular}

FR

R $\quad 3,85$

4,09

4,31

4,52

4,74

4,30

M 2,53

$2,54 \quad 2,45$

$2,34 \quad 2,57$

2,49

$\begin{array}{llllllll}R+M & 3,66 & 4,09 & 4,37 & 4,67 & 5,05 & 4,37 & a\end{array}$

ST

\begin{tabular}{cccccccc}
\hline Média & 3,10 & 3,34 & 3,37 & 3,48 & 3,67 & 3,39 & $B$ \\
\hline Test. & 2,38 & 2,37 & 2,58 & 2,43 & 2,52 & 2,45 & $b$
\end{tabular}

$\begin{array}{llllllll}R & 3,99 & 4,37 & 4,65 & 5,16 & 5,70 & 4,77 & \text { a }\end{array}$

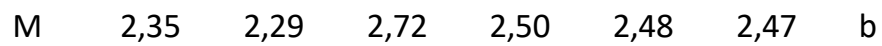

$\begin{array}{lllllll}R+M & 3,93 & 4,63 & 4,86 & 5,33 & 6,19 & 4,99\end{array}$

\begin{tabular}{crrrrrrr}
$\mathrm{R}+\mathrm{M}$ & 3,93 & 4,63 & 4,86 & 5,33 & 6,19 & 4,99 & $\mathrm{a}$ \\
\hline Média & 3,17 & 3,41 & 3,70 & 3,86 & 4,22 & 3,67 & $\mathrm{~A}$ \\
\hline Test. & 0,64 & 0,65 & 0,65 & 0,69 & 0,91 & 0,71 & $\mathrm{~b}$
\end{tabular}

FR

$\begin{array}{llllllll}\mathrm{R} & 0,98 & 1,19 & 1,23 & 1,45 & 1,58 & 1,29 & \mathrm{a}\end{array}$

$\begin{array}{llllllll}M & 0,79 & 0,87 & 0,69 & 0,58 & 0,77 & 0,75 & b\end{array}$

$\begin{array}{llllllll}\mathrm{R}+\mathrm{M} & 1,06 & 1,21 & 1,46 & 1,51 & 1,58 & 1,36 & \mathrm{a}\end{array}$

\begin{tabular}{clllllll} 
Média & 0,87 & 0,98 & 1,02 & 1,06 & 1,16 & 1,03 & $\mathrm{~B}$ \\
\hline Test. & 0,69 & 1,02 & 0,98 & 1,10 & 0,94 & 0,92 & $\mathrm{~b}$
\end{tabular}

ST

$\begin{array}{llllllll}\mathrm{R} & 1,01 & 1,37 & 1,47 & 1,82 & 1,97 & 1,53 & \text { a }\end{array}$

$\begin{array}{llllllll}M & 0,87 & 0,89 & 0,91 & 0,79 & 0,68 & 0,83 & \text { b }\end{array}$

$\begin{array}{lllllll}\mathrm{R}+\mathrm{M} & 1,12 & 1,41 & 1,49 & 1,74 & 1,92 & 1,54\end{array}$

\begin{tabular}{cccccccc} 
Média & 0,92 & 1,17 & 1,21 & 1,36 & 1,38 & 1,21 & \\
\hline Test. & 0,00 & 0,00 & 0,00 & 0,00 & 0,00 & 0,00 & $b$
\end{tabular}

FR

$\begin{array}{llllllll}R & 382 & 423 & 476 & 444 & 506 & 446 & \text { a }\end{array}$

$\begin{array}{llllllll}M & 0,00 & 0,00 & 0,00 & 0,00 & 0,00 & 0,00 & b\end{array}$

\begin{tabular}{clllllll}
$\mathrm{R}+\mathrm{M}$ & 375 & 469 & 596 & 581 & 529 & 510 & $\mathrm{a}$ \\
\hline Média & 189 & 223 & 268 & 256 & 259 & 240 & $\mathrm{~B}$ \\
\hline Test. & 0,00 & 0,00 & 0,00 & 0,00 & 0,00 & 0,00 & $\mathrm{~b}$ \\
$\mathrm{R}$ & 432 & 507 & 602 & 749 & 532 & 564 & $\mathrm{a}$ \\
$\mathrm{M}$ & 0,00 & 0,00 & 0,00 & 0,00 & 0,00 & 0,00 & $\mathrm{~b}$ \\
$\mathrm{R}+\mathrm{M}$ & 455 & 575 & 593 & 751 & 710 & 617 & $\mathrm{a}$ \\
\hline
\end{tabular}

ST 
$\mathrm{N}^{0}$ de Nódulos $\mathrm{NN}^{(2)}$

MSR/MSPA

$\mathrm{MMS} / \mathrm{NN}$

Taxa de Colonização Micorrízica $^{(3)}(\%)$
FR

\begin{tabular}{clllllll}
\hline Média & 222 & 270 & 299 & 375 & 310 & 296 & $\mathrm{~A}$ \\
\hline Test. & 0,00 & 0,00 & 0,00 & 0,00 & 0,00 & 0,00 & $\mathrm{~b}$ \\
$\mathrm{R}$ & 234 & 275 & 280 & 309 & 238 & 267 & $\mathrm{a}$ \\
$\mathrm{M}$ & 0,00 & 0,00 & 0,00 & 0,00 & 0,00 & 0,00 & $\mathrm{~b}$ \\
$\mathrm{R}+\mathrm{M}$ & 238 & 226 & 309 & 272 & 265 & 262 & $\mathrm{a}$ \\
\hline Média & 118 & 125 & 147 & 145 & 126 & 132 & \\
\hline Test. & 0,00 & 0,00 & 0,00 & 0,00 & 0,00 & 0,00 & $\mathrm{~b}$ \\
R & 266 & 302 & 294 & 317 & 269 & 289 & $\mathrm{a}$ \\
M & 0,00 & 0,00 & 0,00 & 0,00 & 0,00 & 0,00 & $\mathrm{~b}$ \\
$\mathrm{R}+\mathrm{M}$ & 224 & 270 & 252 & 271 & 277 & 259 & $\mathrm{a}$ \\
\hline Média & 122 & 143 & 136 & 147 & 136 & 138 & \\
\hline Test. & 0,27 & 0,25 & 0,27 & 0,29 & 0,39 & 0,29 &
\end{tabular}

FR

ST

FR

ST

FR

ST

$\begin{array}{lllllll}\mathrm{R} & 0,25 & 0,29 & 0,28 & 0,32 & 0,33 & 0,29\end{array}$

$\begin{array}{lllllll}M & 0,31 & 0,34 & 0,28 & 0,25 & 0,30 & 0,30\end{array}$

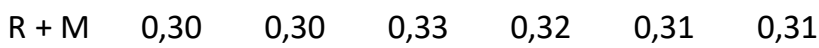

\begin{tabular}{cccccccc} 
Média & 0,28 & 0,29 & 0,29 & 0,30 & 0,33 & 0,30 & $\mathrm{~B}$ \\
\hline Test. & 0,29 & 0,43 & 0,38 & 0,45 & 0,37 & 0,38 & $\mathrm{a}$
\end{tabular}

$\begin{array}{llllllll}\mathrm{R} & 0,25 & 0,31 & 0,32 & 0,35 & 0,35 & 0,32 & \mathrm{ab}\end{array}$

$\begin{array}{lllllll}M & 0,37 & 0,39 & 0,33 & 0,32 & 0,27 & 0,34\end{array}$

$\begin{array}{llllllll}R+M & 0,28 & 0,30 & 0,31 & 0,33 & 0,31 & 0,31 & b\end{array}$

\begin{tabular}{cccccccc} 
Média & 0,30 & 0,36 & 0,33 & 0,36 & 0,32 & 0,34 & $\mathrm{~A}$ \\
\hline Test. & 0,00 & 0,00 & 0,00 & 0,00 & 0,00 & 0,00 & $\mathrm{~b}$
\end{tabular}

$\begin{array}{llllllll}\mathrm{R} & 1,63 & 1,54 & 1,70 & 1,44 & 2,13 & 1,69 & \mathrm{a}\end{array}$

$\begin{array}{lllllll}M & 0,00 & 0,00 & 0,00 & 0,00 & 0,00 & 0,00\end{array}$

$\begin{array}{llllllll}\mathrm{R}+\mathrm{M} & 1,58 & 2,07 & 1,93 & 2,14 & 1,99 & 1,94 & \mathrm{a}\end{array}$

\begin{tabular}{cccccccc} 
Média & 0,80 & 0,90 & 0,91 & 0,89 & 1,03 & 1,43 & $\mathrm{~B}$ \\
\hline Test. & 0,00 & 0,00 & 0,00 & 0,00 & 0,00 & 0,00 & $\mathrm{c}$
\end{tabular}

$\begin{array}{llllllll}R & 1,62 & 1,68 & 2,05 & 2,36 & 1,98 & 1,94 & b\end{array}$

$\begin{array}{llllllll}M & 0,00 & 0,00 & 0,00 & 0,00 & 0,00 & 0,00 & \text { C }\end{array}$

$\begin{array}{llllllll}\mathrm{R}+\mathrm{M} & 2,03 & 2,13 & 2,35 & 2,77 & 2,56 & 2,37 & \mathrm{a} \\ \text { Média } & 0,91 & 0,95 & 1,10 & 1,28 & 1,13 & 1,6 & \mathrm{~A}\end{array}$

$\begin{array}{cccccccc}\text { Test. } & 9,94 & 4,23 & 4,11 & 4,71 & 2,75 & 5,15 & \text { c }\end{array}$

$\begin{array}{llllllll}\mathrm{R} & 3,65 & 2,31 & 4,69 & 8,17 & 8,11 & 4,98 & \mathrm{C}\end{array}$

$\begin{array}{llllllll}M & 18,42 & 18,03 & 14,47 & 19,62 & 16,60 & 17,43 & b\end{array}$

$\begin{array}{llllllll}\mathrm{R}+\mathrm{M} & 17,48 & 24,75 & 20,33 & 29,03 & 17,97 & 21,91 & \mathrm{a}\end{array}$

\begin{tabular}{clllllll} 
Média & 12,37 & 12,33 & 10,90 & 15,38 & 11,36 & 12,37 & \\
\hline Test. & 6,94 & 6,13 & 7,94 & 8,95 & 3,91 & 6,77 & $b$
\end{tabular}

$\begin{array}{llllllll}R & 3,15 & 5,87 & 9,72 & 6,13 & 5,99 & 6,17 & b\end{array}$

$\begin{array}{llllllll}M & 17,92 & 17,67 & 23,16 & 24,30 & 20,77 & 20,76 & \text { a }\end{array}$

$\begin{array}{lllllll}\mathrm{R}+\mathrm{M} & 15,23 & 24,14 & 21,12 & 24,12 & 16,81 & 20,28\end{array}$

$\begin{array}{lllllll}\text { Média } & 10,81 & 13,45 & 15,48 & 15,87 & 11,87 & 13,50\end{array}$

\footnotetext{
(1) Médias seguidas de mesma letra (maiúscula, compara fontes de P; minúscula, compara tratamentos
} microbiológicos) não diferem entre si a nível de $5 \%$ de probabilidade pelo teste de Tukey.

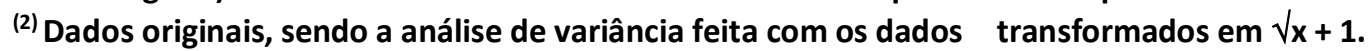

(3) Dados originais, sendo a análise de variância feita com os dados transformados em arco seno $\sqrt{ } \mathrm{x} / 100$.

Diversos são os fatores a serem considerados quanto à escolha da fonte de adubo fosfatado, principalmente em relação à disponibilidade de $\mathrm{P}$ a longo prazo e não só o efeito imediato, como o observado neste trabalho. O primeiro fator norteador de uma tomada de decisão é, sem dúvida, o econômico. O uso eficiente de fertilizantes fosfatados está ligado à aplicação de uma dose que represente o melhor retorno em termos de produção (maior retorno por unidade de $\mathrm{P}$ aplicado). Contudo, considerando-se que o fosfato aplicado no solo tem poucas chances de perda (erosão é a única perda real), não há porque se pensar em doses mínimas, já que o fosfato não aproveitado pela cultura do ano geralmente produz um excelente efeito residual nos 
anos subsequentes. Pela localização geográfica da área (apresentando solos extremamente arenosos), já justifica o emprego da fonte menos solúvel, já que economicamente devemos escolher as fontes de $\mathrm{P}$ que têm menores relações unidades de $\mathrm{P}_{2} \mathrm{O}_{5}$ solúvel/unidade monetária de custo, e que, ao mesmo tempo, disponibilize às árvores outros nutrientes essenciais carentes nos solos de restinga.

Com relação aos efeitos secundários e à dinâmica de $\mathrm{P}$ no solo oriundos das diferentes fontes, é importante observar que se tomarmos nesse trabalho o maior valor numérico de $P$ disponível no solo da fonte de menor reatividade (fosfato de rocha $=120 \mathrm{mg}$ de $\mathrm{P}$ adicionado $/ \mathrm{kg}$ de solo = $16 \mathrm{mg}$ de $\mathrm{P}$ disponível $/ \mathrm{kg}$ de solo) e compararmos com o seu valor similar na outra fonte (supertripo $=30 \mathrm{mg}$ de $\mathrm{P}$ adicionado $/ \mathrm{kg}$ de solo $=14 \mathrm{mg}$ de $\mathrm{P}$ disponível $/ \mathrm{kg}$ de solo), observamos que nos principais parâmetros de crescimento (tabela 2) e, consequentemente, no estabelecimento dessa espécie a campo, praticamente não há diferenças numéricas marcantes em favor da fonte mais reativa.

Esses dados são importantes de serem discutidos em virtude do enfoque tradicional que é dado pelos profissionais das áreas de Agronomia e Floresta (principalmente os extensionistas rurais), que ao escolherem e calcularem suas recomendações de fertilizantes fosfatados apenas levam em consideração o teor de $\mathrm{P}_{2} \mathrm{O}_{5}$ solúvel recomendado nas embalagens dos fabricantes. Em virtude dos vários fatores geológicos, químicos, físicos e biológicos que interferem na reatividade, dinâmica e adsorção do fósforo nos diversos solos nacionais e nas inúmeras condições climáticas reinantes no país, torna-se impossível uma generalização de recomendação de adubação fosfatada, mesmo que seja em nível estadual.

Outro fator importante a se levar em consideração é que a maior parte dos resultados experimentais para adubação fosfática é obtida em condições ideais para os demais nutrientes, nem sempre refletindo a situação real de campo, onde outros nutrientes poderão limitar o desenvolvimento vegetal. Por esses motivos, o experimento realizado neste trabalho, embora sendo conduzido em sistema fechado (vasos) buscou representar o melhor possível as condições in sito, dentro de uma realidade razoável para as aceitações dos modelos aqui propostos.

Os tratamentos microbiológicos tiveram um comportamento igualitário em todos os parâmetros de crescimentos analisados após o transplantio das mudas para os vasos por 59 dias, tendendo a manter a supremacia dos tratamentos que possuíam inoculações com rizóbio isolado ou em conjunto com os fungos micorrízicos arbusculares, quando da fase de produção das mudas nas bandejas tipo plantágio.

Não houve nenhuma diferença entre os tratamentos R e R+M (que foram superiores), nem entre os tratamentos Test. e $\mathrm{M}$ (que foram inferiores) em todos os parâmetros de crescimento, demonstrando que provavelmente a não resposta à inoculação com micorriza, foi devida à baixa colonização e/ou baixa especificidade. Em contrapartida, as plantas responderam à inoculação com Bradyrizobium, demonstrando a importância da seleção e inoculação desses simbiontes.

A relação massa seca das raízes/massa seca da parte aérea (MSR/MSPA) no tratamento com fosfato de rocha não diferiu quanto aos tratamentos microbiológicos, ao passo que no supertriplo os tratamentos $\mathrm{R}+\mathrm{M}$ e Test. tiveram a menor e a maior relações respectivamente. 
A massa dos nódulos secos (MSN), o número de nódulos (NN) e a relação MSN/NN tiveram, em relação aos tratamentos microbiológicos, o mesmo comportamento citado para os parâmetros de crescimento.

Houve pequena taxa de colonização micorrízica (média de 6\%) com os fungos nativos, nos tratamentos sem inoculação com as micorrizas. A taxa de colonização micorrízica nos tratamentos $M$ e $R+M$, apesar de relativamente baixa em termos percentuais (em média 20\%), não difere daquela de diversos trabalhos com acácia mangium, publicados por outros autores.

Os teores de $\mathrm{P}, \mathrm{Ca}, \mathrm{Mg}$, Fe e $\mathrm{Cu}$ (embora este último não significativo) foram maiores nos tratamentos Test. e $\mathrm{M}$, cujos crescimentos vegetais foram inferiores aos demais, indicando um efeito de diluição destes nutrientes nos tecidos das plantas com o aumento do crescimento das mudas. Os demais nutrientes apresentaram um comportamento inverso, mantendo maior teor nas plantas que mais cresceram. O K teve o maior teor em ambas as fontes nos tratamentos com inoculações com micorrizas isoladas $(M)$ ou em conjunto com rizóbio $(R+M)$, fato também observado por FARIA, 1993, trabalhando com a mesma espécie, indicando o papel ativo da micorriza na absorção deste nutriente. Todos os nutrientes tiveram maiores acúmulos significativos nos tratamentos $\mathrm{R}$ e $\mathrm{R}+\mathrm{M}$, por produzirem uma maior massa seca da parte aérea, indicando que o principal fator limitante deste solo foi o nitrogênio.

\subsection{Influência dos níveis de fósforo}

Visando facilitar o raciocínio das análises da influência das doses de $P$, torna-se necessário o estabelecimento de nomenclaturas para os tratamentos realizados, que passam a ser os seguintes: FrT (fosfato de rocha + testemunha); FrR (fosfato de rocha + rizóbio); FrM (fosfato de rocha + micorriza); FrRM (fosfato de rocha + rizóbio + micorriza); StT (supertriplo + testemunha); StR (supertriplo + rizóbio); StM (supertriplo + micorriza) e StRM (supertriplo + rizóbio + micorriza).

Os resultados de crescimento, nodulação e colonização da Acacia mangium Willd, em função das doses de P aplicadas, encontram-se na tabela 2. Com exceção do tratamento FrRM para altura das plantas, todos os demais tratamentos que receberam inoculação com rizóbio isolado (R) ou em conjunto com micorriza (RM), nas duas fontes (F1 e F2), em todos os parâmetros de crescimento analisados, aumentaram com a adubação fosfatada, apresentando respostas lineares às doses de $\mathrm{P}$ adicionadas $\mathrm{e}$, por este motivo, não foi possível estabelecer os níveis críticos para os principais parâmetros dessa espécie, que responderiam positivamente aos maiores acréscimos de $\mathrm{P}$ ao solo.

As equações de regressão ajustadas para altura, diâmetro à altura do colo, massa seca da parte aérea e massa seca das raízes, evidenciam uma significativa resposta da espécie à adubação fosfatada. Para esses quatro parâmetros, verifica-se pelo ajuste das equações de regressão linear, que as doses de $\mathrm{P}$ para obtenção de um máximo biológico seriam ainda maiores.

Em média, os parâmetros de crescimento aqui analisados tiveram incrementos percentuais em relação à testemunha muito inferiores aos incrementos citados por outros autores. Nesses trabalhos, não havia limitações à testemunha e aos outros tratamentos quanto ao nitrogênio (elemento neste trabalho muito limitante nos tratamentos sem inoculação com rizóbio) e, na sua grande maioria, esses experimentos foram conduzidos conjuntamente com adubações nitrogenadas, indicando que essas plantas respondem também a $\mathrm{N}$ e que têm um potencial de 
crescimento muito maior. Este potencial pode também ser incrementado com a inoculação de melhores estirpes de Rhizobium.

A massa dos nódulos secos teve uma resposta quadrática em FrRM e StR e linear em StRM. $O$ decréscimo observado próximo à dose $60 \mathrm{mg}$ adicionado de $\mathrm{P} / \mathrm{g}$ de solo nas duas fontes, sugere ser este limite de benefício da absorção de $\mathrm{P}$ com efeito benéfico a esse parâmetro e ao número de nódulos. $O$ aumento do número e o peso dos nódulos e da atividade específica da nitrogenase em espécies florestais são frequentemente associados ao aumento da nutrição fosfatada, uma vez que a nitrogenase é dependente de ATP, requerendo, portanto, um elevado suprimento de P. Não ocorreu nodulação nos tratamentos que não receberam fontes de inóculos bacterianos, provavelmente devido à pobreza em inóculos indígenas do solo muito degradado de restinga utilizado nos vasos. Não se encontraram também ajustes de equações para o parâmetro número de nódulos (NN).

A taxa de colonização micorrízica, embora considerada baixa, parece ser adequada a esta espécie. Não foram encontrados ajustes de regressões também para este parâmetro.

Tabela 3: Médias e testes de médias dos parâmetros nutricionais (teores e acúmulo de macronutrientes na parte aérea), observadas em mudas de Acacia mangium Willd, submetidas a inoculações com Bradyrhizobium e fungos micorrízicos arbusculares, em diferentes fontes e níveis de Fósforo, aos 59 dias após o transplantio para vasos com solo de restinga (média de 4 repetições - valores por planta):

\begin{tabular}{|c|c|c|c|c|c|c|c|c|c|}
\hline \multirow{2}{*}{ Parâmetro } & \multirow{2}{*}{$\begin{array}{l}\text { Fonte de } \\
\text { Fósforo }^{(1)}\end{array}$} & \multirow{2}{*}{$\mathrm{TM}^{(1)}$} & \multicolumn{5}{|c|}{ Níveis de $\mathrm{P}$ (mg P. $\mathrm{Kg}^{-1}$ de solo) } & \multirow{2}{*}{\multicolumn{2}{|c|}{ Média }} \\
\hline & & & 0 & 15 & 30 & 60 & 120 & & \\
\hline \multirow[t]{10}{*}{$\mathrm{N}\left(\mathrm{g} \cdot \mathrm{Kg}^{-1}\right)$} & FR & Test. & 11,51 & 13,73 & 14,42 & 12,99 & 13,29 & 13,19 & C \\
\hline & & $\mathrm{R}$ & 23,28 & 21,91 & 21,75 & 21,68 & 21,64 & 22,05 & a \\
\hline & & $\mathrm{M}$ & 16,53 & 15,79 & 16,68 & 16,63 & 13,79 & 15,88 & $b$ \\
\hline & & $R+M$ & 24,77 & 23,75 & 22,67 & 22,20 & 21,80 & 23,94 & a \\
\hline & & Média & 19,02 & 18,79 & 18,88 & 18,37 & 17,63 & 18,54 & \\
\hline & ST & Test. & 14,29 & 14,24 & 14,28 & 14,80 & 14,73 & 14,47 & $b$ \\
\hline & & $\mathrm{R}$ & 23,67 & 22,89 & 21,87 & 22,45 & 23,62 & 22,90 & a \\
\hline & & $M$ & 17,07 & 16,88 & 17,47 & 14,66 & 14,69 & 16,15 & $b$ \\
\hline & & $R+M$ & 23,54 & 22,66 & 21,86 & 22,79 & 22,97 & 22,76 & a \\
\hline & & Média & 19,64 & 19,17 & 18,87 & 18,67 & 19,99 & 19,07 & \\
\hline \multirow[t]{10}{*}{ N Total (mg/planta) } & FR & Test. & 2,72 & 3,61 & 3,41 & 3,14 & 3,03 & 3,18 & $b$ \\
\hline & & $\mathrm{R}$ & 8,90 & 8,92 & 9,30 & 9,84 & 10,24 & 9,44 & a \\
\hline & & $M$ & 4,22 & 4,02 & 4,08 & 3,89 & 3,58 & 3,95 & $b$ \\
\hline & & $R+M$ & 9,08 & 9,67 & 9,79 & 10,45 & 11,04 & 10,01 & a \\
\hline & & Média & 6,23 & 6,56 & 6,64 & 6,83 & 6,97 & 6,65 & $B$ \\
\hline & ST & Test. & 3,39 & 3,36 & 3,65 & 3,59 & 3,71 & 3,54 & $b$ \\
\hline & & $\mathrm{R}$ & 9,50 & 10,04 & 10,15 & 11,61 & 13,56 & 10,97 & a \\
\hline & & $\mathrm{M}$ & 4,03 & 3,87 & 4,76 & 3,64 & 3,64 & 3,99 & b \\
\hline & & $R+M$ & 9,19 & 10,83 & 10,69 & 12,03 & 14,29 & 11,41 & a \\
\hline & & Média & 6,53 & 7,03 & 7,31 & 7,72 & 8,80 & 7,48 & $A$ \\
\hline \multirow[t]{10}{*}{$\mathrm{P}\left(\mathrm{g} . \mathrm{Kg}^{-1}\right)$} & FR & Test. & 1,84 & 2,02 & 2,07 & 2,61 & 2,31 & 2,17 & $a$ \\
\hline & & $\mathrm{R}$ & 1,05 & 1,40 & 1,61 & 1,62 & 1,87 & 1,51 & $b$ \\
\hline & & $\mathrm{M}$ & 2,05 & 2,46 & 2,55 & 2,82 & 2,32 & 2,43 & a \\
\hline & & $R+M$ & 1,03 & 1,67 & 1,72 & 1,73 & 2,12 & 1,65 & $b$ \\
\hline & & Média & 1,48 & 1,89 & 1,99 & 2,19 & 2,15 & 1,94 & $B$ \\
\hline & ST & Test. & 1,86 & 2,30 & 2,61 & 3,15 & 2,39 & 2,46 & $a$ \\
\hline & & $\mathrm{R}$ & 1,07 & 1,25 & 1,57 & 1,63 & 2,34 & 1,57 & $b$ \\
\hline & & $M$ & 2,18 & 2,69 & 2,66 & 3,03 & 2,32 & 2,58 & a \\
\hline & & $R+M$ & 1,11 & 1,66 & 1,88 & 1,77 & 2,40 & 1,76 & $b$ \\
\hline & & Média & 1,55 & 1,97 & 2,18 & 2,39 & 2,36 & 2,09 & $A$ \\
\hline
\end{tabular}


P Total (mg/planta)

$\mathrm{K}\left(\mathrm{g} . \mathrm{Kg}^{-1}\right)$

K Total (mg/planta)

Ca $\left(\mathrm{g} \cdot \mathrm{Kg}^{-1}\right)$

Ca Total (mg/planta)

$\mathrm{Mg}\left(\mathrm{g} . \mathrm{Kg}^{-1}\right)$
FR

\begin{tabular}{clllllll}
\hline Test. & 4,38 & 5,30 & 4,90 & 6,26 & 5,15 & 5,20 & $\mathrm{c}$ \\
R & 4,16 & 5,77 & 6,94 & 7,34 & 8,80 & 6,60 & $\mathrm{ab}$ \\
M & 5,12 & 6,35 & 6,03 & 6,63 & 6,07 & 6,04 & $\mathrm{bc}$ \\
$\mathrm{R}+\mathrm{M}$ & 3,80 & 6,81 & 7,42 & 8,03 & 10,72 & 7,35 & $\mathrm{a}$ \\
\hline Média & 4,36 & 6,06 & 6,32 & 7,07 & 7,68 & 6,30 & $\mathrm{~B}$ \\
\hline Test. & 4,44 & 5,51 & 6,73 & 7,71 & 6,10 & 6,10 & $\mathrm{c}$ \\
R & 4,29 & 5,45 & 7,11 & 8,37 & 13,17 & 7,68 & $\mathrm{~b}$ \\
M & 5,15 & 6,17 & 7,32 & 7,47 & 5,80 & 6,38 & $\mathrm{c}$
\end{tabular}

$\begin{array}{llllllll}R+M & 4,40 & 7,66 & 8,61 & 9,43 & 14,75 & 8,97 & a\end{array}$

FR

\begin{tabular}{clllllll} 
Média & 4,57 & 6,20 & 7,44 & 8,24 & 9,96 & 6,99 & $\mathrm{~A}$ \\
\hline Test. & 12,40 & 12,10 & 11,90 & 12,00 & 12,20 & 12,10 & $\mathrm{~b}$
\end{tabular}

$\begin{array}{llllllll}\mathrm{R} & 12,50 & 12,20 & 11,90 & 12,50 & 13,00 & 12,30 & \text { b }\end{array}$

$\begin{array}{llllllll}M & 14,40 & 13,20 & 12,60 & 14,00 & 13,20 & 13,50 & \text { a }\end{array}$

$\begin{array}{llllllll}R+M & 14,10 & 13,60 & 12,70 & 13,50 & 14,60 & 13,70 & a\end{array}$

ST

$\begin{array}{llllllll}\text { Média } & 13,30 & 12,80 & 12,30 & 13,00 & 13,20 & 12,91\end{array}$

$\begin{array}{llllllll}\text { Test. } & 13,10 & 13,00 & 12,70 & 12,90 & 13,00 & 12,90 & \text { ab }\end{array}$

$\begin{array}{llllllll}R & 12,40 & 12,20 & 12,00 & 12,20 & 13,00 & 12,40 & b\end{array}$

$\begin{array}{llllllll}M & 14,10 & 13,60 & 13,00 & 13,60 & 14,30 & 13,70 & \text { a }\end{array}$

$\begin{array}{llllllll}\mathrm{R}+\mathrm{M} & 14,20 & 13,10 & 12,90 & 13,70 & 13,00 & 13,40 & \text { a }\end{array}$

$\begin{array}{lllllll}\text { Média } & 13,40 & 13,00 & 12,60 & 13,10 & 13,30 & 13,11\end{array}$

FR

$\begin{array}{llllllll}\text { Test. } & 29,25 & 32,23 & 28,10 & 28,77 & 27,87 & 29,24 & b\end{array}$

$\begin{array}{llllllll}R & 43,43 & 50,10 & 51,22 & 58,47 & 61,62 & 52,97 & \text { a }\end{array}$

$\begin{array}{llllllll}M & 36,53 & 34,06 & 30,56 & 32,97 & 34,74 & 33,77 & \text { b }\end{array}$

$\begin{array}{llllllll}\mathrm{R}+\mathrm{M} & 51,55 & 55,87 & 55,20 & 63,24 & 73,56 & 59,88 & \mathrm{a}\end{array}$

$\begin{array}{llllllll}\text { Média } & 40,19 & 43,07 & 41,27 & 45,86 & 49,45 & 43,97 & \text { B }\end{array}$

ST

\begin{tabular}{cccccccc}
\hline Test. & 31,32 & 30,72 & 31,91 & 31,29 & 32,66 & 31,58 & $\mathrm{c}$ \\
R & 49,41 & 53,53 & 54,84 & 63,15 & 73,96 & 58,98 & b
\end{tabular}

$\begin{array}{llllllll}M & 33,27 & 31,33 & 35,62 & 33,80 & 37,72 & 33,95 & c\end{array}$

$\begin{array}{llllllll}\mathrm{R}+\mathrm{M} & 55,91 & 59,41 & 61,96 & 74,43 & 80,26 & 66,39 & \text { a }\end{array}$

$\begin{array}{clllllll}\text { Média } & 42,42 & 43,75 & 46,08 & 50,67 & 55,65 & 47,72 & \text { A } \\ \text { Test. } & 19,5 & 19,7 & 17,8 & 19,7 & 17,2 & 18,8 & \text { a }\end{array}$

FR

$\begin{array}{llllllll}\mathrm{R} & 18,9 & 18,5 & 17,3 & 19,0 & 18,6 & 18,5 & \mathrm{ab}\end{array}$

M $17,3 \quad 17,4 \quad 17,4 \quad 18,3 \quad 17,2 \quad 17,5 \quad$ ab

$\begin{array}{llllllll}\mathrm{R}+\mathrm{M} & 17,1 & 17,3 & 18,0 & 17,4 & 16,9 & 17,3 & \mathrm{~b}\end{array}$

\begin{tabular}{clllllll}
\hline Média & 18,2 & 18,2 & 17,6 & 18,6 & 17,5 & 18,04 & $\mathrm{~B}$ \\
\hline Test. & 19,2 & 19,2 & 18,3 & 20,1 & 18,7 & 19,1 & $\mathrm{ab}$
\end{tabular}

ST

$\begin{array}{llllllll}R & 18,9 & 20,2 & 19,7 & 19,9 & 19,9 & 19,7 & \text { a }\end{array}$

$\begin{array}{lllllll}M & 17,9 & 17,1 & 18,2 & 16,6 & 18,9 & 17,7\end{array}$

$\begin{array}{llllllll}\mathrm{R}+\mathrm{M} & 17,7 & 19,2 & 17,9 & 17,6 & 18,0 & 18,1 & \mathrm{~b}\end{array}$

$\begin{array}{llllllll}\text { Média } & 18,4 & 18,9 & 18,5 & 18,5 & 18,9 & 18,67 & \text { A }\end{array}$

FR

Test.

$\begin{array}{llllllll}\text { R } & 73,49 & 76,62 & 74,73 & 86,50 & 88,22 & 79,91 & \text { a }\end{array}$

$\begin{array}{llllllll}M & 43,58 & 44,57 & 42,61 & 43,22 & 44,34 & 43,66 & \text { b }\end{array}$

$\begin{array}{llllllll}\mathrm{R}+\mathrm{M} & 62,97 & 71,01 & 80,00 & 81,88 & 85,66 & 76,30 & \mathrm{a}\end{array}$

\begin{tabular}{llllllll} 
Média & 56,54 & 61,01 & 59,92 & 64,76 & 64,41 & 61,32 & B \\
\hline
\end{tabular}

ST

$\begin{array}{lllllllll}\text { Test. } & 46,32 & 45,42 & 46,76 & 48,84 & 46,86 & 46,84 & \text { b }\end{array}$

$\begin{array}{llllllll}\text { R } & 75,12 & 88,18 & 90,86 & 102,6 & 114,8 & 94,33 & \text { a }\end{array}$

$\begin{array}{llllllll}M & 42,03 & 39,23 & 49,68 & 41,60 & 46,86 & 43,88 & \text { b }\end{array}$

$\begin{array}{llllllll}\mathrm{R}+\mathrm{M} & 69,46 & 88,44 & 88,49 & 93,89 & 111,2 & 90,30 & \mathrm{a}\end{array}$

\begin{tabular}{clllllll}
\hline Média & 58,23 & 65,32 & 68,95 & 70,75 & 79,93 & 68,84 & $\mathrm{~A}$ \\
\hline Test. & 2,60 & 2,65 & 2,85 & 2,95 & 2,55 & 2,70 & $\mathrm{a}$ \\
$\mathrm{R}$ & 1,85 & 1,90 & 1,90 & 1,95 & 1,90 & 1,90 & $\mathrm{~b}$ \\
$\mathrm{M}$ & 2,40 & 2,50 & 2,65 & 2,70 & 2,55 & 2,60 & $\mathrm{a}$ \\
$\mathrm{R}+\mathrm{M}$ & 1,55 & 1,65 & 1,75 & 1,85 & 1,75 & 1,70 & $\mathrm{~b}$ \\
\hline Média & 2,10 & 2,15 & 2,30 & 2,35 & 2,20 & 2,23 & \\
\hline Test. & 2,60 & 2,75 & 2,80 & 2,90 & 2,75 & 2,75 & $\mathrm{a}$
\end{tabular}

FR 


\begin{tabular}{|c|c|c|c|c|c|c|c|c|c|}
\hline & & $\mathrm{R}$ & 1,90 & 1,70 & 1,95 & 1,80 & 1,75 & 1,85 & $b$ \\
\hline & & $M$ & 2,35 & 2,65 & 2,80 & 2,65 & 2,65 & 2,65 & a \\
\hline & & $R+M$ & 1,60 & 1,65 & 1,90 & 1,80 & 1,60 & 1,70 & $b$ \\
\hline & & Média & 2,10 & 2,20 & 2,35 & 2,30 & 2,20 & 2,24 & \\
\hline \multirow[t]{10}{*}{ Mg Total(mg/planta) } & FR & Test. & 6,11 & 7,03 & 6,72 & 7,12 & 5,54 & 6,50 & bc \\
\hline & & $\mathrm{R}$ & 7,12 & 7,80 & 8,22 & 8,89 & 9,10 & 8,22 & $a$ \\
\hline & & $M$ & 6,07 & 6,44 & 6,55 & 6,38 & 6,55 & 6,40 & c \\
\hline & & $R+M$ & 5,69 & 6,89 & 7,79 & 8,68 & 8,94 & 7,60 & $a b$ \\
\hline & & Média & 6,25 & 7,04 & 7,32 & 7,76 & 7,53 & 7,18 & $B$ \\
\hline & ST & Test. & 6,22 & 6,58 & 7,10 & 7,11 & 6,96 & 6,79 & $b$ \\
\hline & & $\mathrm{R}$ & 7,66 & 7,51 & 8,96 & 9,33 & 9,95 & 8,68 & a \\
\hline & & $M$ & 5,61 & 6,12 & 7,66 & 6,55 & 6,60 & 6,50 & $b$ \\
\hline & & $R+M$ & 6,48 & 7,60 & 9,06 & 9,54 & 9,87 & 8,51 & a \\
\hline & & Média & 6,49 & 6,95 & 8,19 & 8,13 & 8,35 & 7,62 & $A$ \\
\hline
\end{tabular}

${ }^{(1)}$ Médias seguidas de mesma letra (maiúscula, compara fontes de P; minúscula, compara tratamentos microbiológicos) não diferem entre si a nível de $5 \%$ de probabilidade pelo teste de Tukey.

Tabela 4: Médias e testes de médias dos parâmetros nutricionais (teores e acúmulo de micronutrientes na parte aérea), observadas em mudas de Acacia mangium Willd, submetidas à inoculações com Bradyhizobium e fungos micorrízicos arbusculares, em diferentes fontes e níveis de fósforo, aos 59 dias após o transplantio para vasos com solo de restinga (média de 4 repetições -valores por planta):

\begin{tabular}{|c|c|c|c|c|c|c|c|c|c|}
\hline \multirow{2}{*}{ Parâmetro } & \multirow{2}{*}{$\begin{array}{l}\text { Fonte de } \\
\text { Fósforo }^{(1)}\end{array}$} & \multirow{2}{*}{$\mathrm{TM}^{(1)}$} & \multicolumn{5}{|c|}{ Níveis de $\mathrm{P}$ (mg P. $\mathrm{Kg}^{-1}$ de solo) } & \multirow{2}{*}{\multicolumn{2}{|c|}{ Média }} \\
\hline & & & 0 & 15 & 30 & 60 & 120 & & \\
\hline \multirow[t]{10}{*}{$\mathrm{Cu}\left(\mathrm{mg} \cdot \mathrm{Kg}^{-1}\right)$} & FR & Test. & 8,75 & 8,00 & 7,77 & 7,50 & 7,12 & 7,82 & \\
\hline & & $\mathrm{R}$ & 8,50 & 8,50 & 7,77 & 7,00 & 6,62 & 7,68 & \\
\hline & & $\mathrm{M}$ & 9,25 & 8,50 & 7,25 & 7,00 & 6,50 & 7,70 & \\
\hline & & $R+M$ & 7,25 & 8,37 & 8,12 & 7,37 & 6,75 & 7,57 & \\
\hline & & Média & 8,44 & 8,34 & 7,72 & 7,22 & 6,74 & 7,69 & \\
\hline & ST & Test. & 8,35 & 7,75 & 7,62 & 7,50 & 7,37 & 7,72 & \\
\hline & & $\mathrm{R}$ & 8,50 & 7,62 & 7,87 & 7,37 & 7,62 & 7,70 & \\
\hline & & $\mathrm{M}$ & 9,12 & 9,37 & 7,12 & 6,87 & 6,75 & 7,85 & \\
\hline & & $R+M$ & 7,37 & 8,00 & 7,62 & 7,37 & 7,00 & 7,47 & \\
\hline & & Média & 8,33 & 8,18 & 7,55 & 7,27 & 7,18 & 7,68 & \\
\hline \multirow[t]{10}{*}{ Cu Total ( $\mu \mathrm{g} /$ planta) } & FR & Test. & 20,55 & 20,60 & 18,12 & 18,07 & 16,28 & 18,73 & $b$ \\
\hline & & $\mathrm{R}$ & 33,15 & 35,13 & 33,79 & 32,09 & 31,08 & 33,05 & a \\
\hline & & $\mathrm{M}$ & 23,41 & 21,60 & 17,39 & 16,29 & 16,57 & 19,05 & $b$ \\
\hline & & $R+M$ & 26,61 & 33,95 & 33,84 & 33,86 & 33,65 & 32,38 & a \\
\hline & & Média & 25,93 & 27,82 & 25,79 & 25,08 & 24,40 & 25,80 & \\
\hline & ST & Test. & 19,86 & 18,00 & 20,94 & 18,29 & 18,72 & 19,16 & $b$ \\
\hline & & $\mathrm{R}$ & 33,85 & 30,68 & 35,97 & 37,28 & 43,36 & 36,23 & $\mathrm{a}$ \\
\hline & & $M$ & 21,51 & 21,47 & 19,51 & 16,85 & 16,63 & 19,19 & $b$ \\
\hline & & $R+M$ & 29,04 & 37,78 & 35,93 & 38,94 & 43,15 & 36,97 & a \\
\hline & & Média & 26,06 & 26,98 & 28,09 & 27,84 & 30,46 & 27,89 & \\
\hline \multirow[t]{10}{*}{$\mathrm{Mn}\left(\mathrm{mg} \cdot \mathrm{Kg}^{-1}\right)$} & FR & Test. & 44,0 & 48,0 & 45,7 & 44,0 & 41,0 & 44,6 & $b$ \\
\hline & & $\mathrm{R}$ & 55,5 & 51,0 & 48,0 & 51,2 & 49,5 & 51,1 & a \\
\hline & & $\mathrm{M}$ & 36,7 & 39,2 & 39,5 & 34,0 & 31,5 & 36,2 & $c$ \\
\hline & & $\mathrm{R}+\mathrm{M}$ & 46,5 & 42,7 & 44,0 & 39,7 & 33,7 & 41,3 & $\mathrm{bc}$ \\
\hline & & Média & 45,7 & 45,2 & 44,3 & 42,5 & 38,9 & 43,3 & $\mathrm{~B}$ \\
\hline & ST & Test. & 45,0 & 46,2 & 45,5 & 43,7 & 41,2 & 44,3 & $b$ \\
\hline & & $\mathrm{R}$ & 57,2 & 56,5 & 56,5 & 55,5 & 51,7 & 55,5 & a \\
\hline & & $M$ & 41,0 & 42,0 & 41,5 & 37,2 & 35,0 & 39,3 & $b$ \\
\hline & & $\mathrm{R}+\mathrm{M}$ & 49,0 & 47,2 & 46,2 & 37,5 & 38,0 & 43,6 & $b$ \\
\hline & & Média & 48,1 & 47,9 & 47,4 & 43,5 & 41,5 & 45,7 & $A$ \\
\hline Mn Total ( $\mu \mathrm{g} /$ planta) & FR & Test. & 104,3 & 127,2 & 107,7 & 106,1 & 95,7 & 108,2 & $\mathrm{C}$ \\
\hline
\end{tabular}


Fe $\left(\mathrm{mg} \cdot \mathrm{Kg}^{-1}\right)$

Fe Total ( $\mu \mathrm{g} / \mathrm{planta})$

$\mathrm{Zn}\left(\mathrm{mg} . \mathrm{Kg}^{-1}\right)$

Zn Total ( $\mu \mathrm{g} /$ planta)

$\begin{array}{clllllll}\mathrm{R} & 213,6 & 206,9 & 208,1 & 233,9 & 234,2 & 219,3 & \mathrm{a} \\ \mathrm{M} & 92,3 & 99,8 & 93,5 & 79,6 & 79,9 & 89,1 & \mathrm{c} \\ \mathrm{R}+\mathrm{M} & 170,4 & 176,7 & 199,9 & 185,9 & 170,3 & 180,6 & \mathrm{~b}\end{array}$

ST

\begin{tabular}{cccccccc} 
Média & 145,1 & 152,6 & 152,3 & 151,3 & 145,1 & 149,3 & $B$ \\
\hline Test. & 106,9 & 111,9 & 113,8 & 106,1 & 103,4 & 108,4 & $\mathrm{C}$
\end{tabular}

$\begin{array}{llllllll}\text { R } & 228,3 & 246,9 & 258,6 & 285,5 & 299,2 & 263,7 & \text { a }\end{array}$

$\begin{array}{llllllll}M & 95,9 & 96,0 & 112,5 & 92,3 & 86,8 & 96,7 & \text { c }\end{array}$

$\begin{array}{llllllll}R+M & 190,9 & 213,4 & 228,1 & 204,9 & 235,2 & 214,5 & b\end{array}$

\begin{tabular}{clllllll} 
Média & 155,5 & 167,1 & 178,2 & 172,2 & 181,2 & 170,8 & A \\
\hline Test. & 212 & 215 & 217 & 247 & 225 & 223 & a
\end{tabular}

FR

ST

$\begin{array}{llllllll}\mathrm{R} & 115 & 127 & 170 & 225 & 237 & 175 & \mathrm{~b} \\ \mathrm{M} & 210 & 200 & 242 & 235 & 242 & 226 & \mathrm{a}\end{array}$

$\begin{array}{llllllll}R+M & 150 & 150 & 195 & 225 & 250 & 194\end{array}$

\begin{tabular}{clllllll}
\hline Média & 172 & 173 & 206 & 233 & 238 & 205 & \\
\hline Test. & 207 & 192 & 222 & 240 & 245 & 221 & a
\end{tabular}

$\begin{array}{llllllll}R & 127 & 190 & 217 & 205 & 240 & 196 & b\end{array}$

$\begin{array}{llllllll}M & 207 & 202 & 240 & 237 & 235 & 224 & \text { a }\end{array}$

$\begin{array}{llllllll}\mathrm{R}+\mathrm{M} & 155 & 147 & 240 & 242 & 275 & 212 & \mathrm{ab}\end{array}$

FR

\begin{tabular}{clllllll}
\hline Média & 174 & 183 & 229 & 231 & 249 & 213 & \\
Test. & 500,1 & 582,2 & 518,5 & 596,9 & 519,1 & 543,4 & b
\end{tabular}

$\begin{array}{llllllll}R & 448,3 & 531,1 & 730,9 & 1020 & 1118 & 769,8 & \text { a }\end{array}$

$\begin{array}{llllllll}M & 534,6 & 509,1 & 606,1 & 548,8 & 617,9 & 563,3 & \text { b }\end{array}$

$\begin{array}{llllllll}\mathrm{R}+\mathrm{M} & 553,5 & 607,6 & 863,3 & 1053 & 1259 & 867,6 & \mathrm{a}\end{array}$

\begin{tabular}{llllllll} 
Média & 509,1 & 557,5 & 679,7 & 805,0 & 878,7 & 686,0 & B \\
\hline
\end{tabular}

ST

$\begin{array}{llllllll}\text { Test. } & 497,6 & 459,6 & 571,9 & 584,0 & 610,7 & 544,8 & \text { b }\end{array}$

$\begin{array}{llllllll}R & 505,8 & 827,9 & 998,1 & 1047 & 1382 & 952,3 & \text { a }\end{array}$

$M \quad 490,2 \quad 465,1 \quad 656,8 \quad 595,1 \quad 583,3 \quad 558,1 \quad b$

\begin{tabular}{cccccccc}
$\mathrm{R}+\mathrm{M}$ & 605,4 & 649,4 & 1181 & 1275 & 1708 & 1083 & $\mathrm{a}$ \\
\hline Média & 524,8 & 600,5 & 852,1 & 875,5 & 1071 & 785,0 & $\mathrm{~A}$
\end{tabular}

FR

$\begin{array}{llllllll}\text { Test. } & 20,25 & 16,75 & 16,00 & 16,00 & 15,75 & 16,95 & \text { b }\end{array}$

$\begin{array}{llllllll}\mathrm{R} & 23,25 & 21,50 & 18,75 & 20,50 & 21,75 & 21,15 & \text { a }\end{array}$

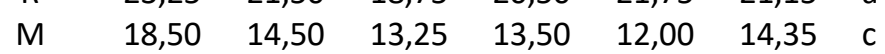

\begin{tabular}{llllllll}
$\mathrm{R}+\mathrm{M}$ & 20,25 & 19,75 & 18,25 & 18,00 & 19,50 & 19,15 & $\mathrm{ab}$ \\
\hline
\end{tabular}

\begin{tabular}{cllllllll}
\hline Média & 50,56 & 18,18 & 16,56 & 17,00 & 17,25 & 17,90 & \\
\hline Test. & 20,00 & 17,50 & 16,75 & 16,50 & 15,50 & 17,25 & bc
\end{tabular}

ST

$\begin{array}{llllllll}R & 21,50 & 21,50 & 19,00 & 17,00 & 18,50 & 19,50 & \text { ab }\end{array}$

$\begin{array}{llllllll}M & 20,00 & 15,75 & 13,75 & 14,75 & 13,50 & 15,55 & \text { c }\end{array}$

$\begin{array}{lllllll}\mathrm{R}+\mathrm{M} & 20,75 & 20,50 & 18,75 & 19,75 & 20,50 & 20,05\end{array}$

\begin{tabular}{cccccccc}
$\mathrm{R}+\mathrm{M}$ & 20,75 & 20,50 & 18,75 & 19,75 & 20,50 & 20,05 & $\mathrm{a}$ \\
\hline Média & 50,56 & 18,81 & 17,06 & 17,00 & 17,00 & 18,09 & \\
\hline Test. & 47,56 & 43,84 & 37,55 & 38,24 & 34,91 & 40,42 & $\mathrm{~b}$
\end{tabular}

FR

$\begin{array}{llllllll}\text { R } & 87,16 & 85,29 & 80,37 & 91,38 & 102,0 & 89,24 & \text { a }\end{array}$

$\begin{array}{llllllll}M & 46,32 & 36,32 & 31,81 & 31,46 & 30,72 & 35,33 & \text { b }\end{array}$

$\begin{array}{llllllll}\mathrm{R}+\mathrm{M} & 74,27 & 81,61 & 77,21 & 83,57 & 97,96 & 82,93 & \mathrm{a}\end{array}$

\begin{tabular}{cccccccc} 
Média & 63,83 & 61,77 & 56,74 & 61,16 & 66,40 & 61,98 & B \\
\hline Test. & 47,35 & 41,44 & 42,18 & 40,04 & 38,78 & 41,96 & b
\end{tabular}

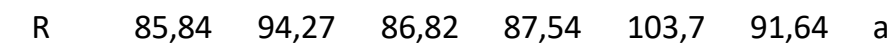

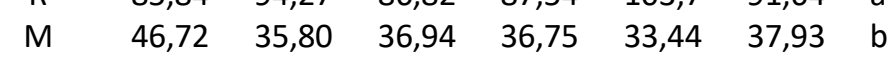

$\begin{array}{llllllll}R+M & 81,53 & 95,31 & 87,18 & 103,2 & 126,2 & 98,69 & \text { a }\end{array}$

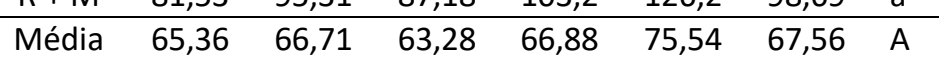

\footnotetext{
${ }^{(1)}$ Médias seguidas de mesma letra (maiúscula, compara fontes de P; minúscula, compara tratamentos
} microbiológicos) não diferem entre si a nível de $5 \%$ de probabilidade pelo teste de Tukey.

Praticamente não foram encontrados ajustes para o teor de N. O N acumulado teve ajustes acumulados para StR e StRM. O teor e o acúmulo de fósforo tiveram comportamentos muito similares, onde nos tratamentos que dispunham de inoculação com rizóbio e ambas as fontes (FrR, 
FrRM, StR e StRM) tiveram respostas lineares às doses crescentes de $P$. Isso indica que as plantas ainda absorveriam mais $P$ se a dose máxima fosse superior à maior dose empregada neste experimento. Quanto aos tratamentos sem rizóbio (FrM, StT e StM), a resposta foi quadrática, não significando por isso ter-se atingido o máximo de produção biológica e sim que as plantas não cresceram por falta de $\mathrm{N}$; que as maiores doses de $\mathrm{P}$ nesses casos tiveram efeitos tóxicos para os vegetais.

O Ca não teve ajustes aceitáveis e o $\mathrm{K}$ e $\mathrm{Mg}$ tiveram poucos ajustes, não dignos de tendência, por apresentarem um coeficiente de determinação muito baixo e, logicamente, por não terem em seus pontos muitas aderências às curvas dos modelos propostos.

Os teores dos micronutrientes, quando apresentaram ajustes, tiveram uma resposta linear em relação às doses crescentes de aplicação de $\mathrm{P}$ no solo. Isto indica que um desenvolvimento sempre crescente da acácia mangium neste trabalho, até a dose mais alta, foi também acompanhado por um melhor estado nutricional das plantas e que, nesses níveis trabalhados de $P$, este elemento não inibiu a absorção de outros nutrientes, principalmente os micros. $\mathrm{O} F$, em todos os tratamentos que dispunham de rizóbio, apresentou um comportamento linear, fato que também ocorreu no tratamento StT. O Cu e o $\mathrm{Zn}$ tiveram comportamentos similares quando inoculados só com a micorriza isolada (FrM e StM). O Mn apenas apresentou essa tendência quando os dois simbiontes estavam inoculados (FrRM e StRM).

Praticamente todos os acúmulos de macro e micronutrientes na parte aérea da acácia mangium (Tabelas 3 e 4) tiveram uma resposta linear às doses de $P$ aplicadas nos tratamentos com rizóbio isolado ou com dupla inoculação (FrR, FrRM, StR e StRM). Isso se deve, logicamente, a uma maior produção de matéria seca nesses tratamentos e consequentemente a um maior acúmulo de elementos na massa acumulada.

\section{CONCLUSÃO}

Em relação aos tratamentos microbiológicos, as fontes de fósforo e aos níveis de $\mathrm{P}$ e suas interações em que foram desenvolvidos esses experimentos, pode-se chegar às seguintes conclusões:

- O superfosfato triplo como fonte de P proporcionou maior crescimento em altura, massa seca da parte aérea (MSPA), massa seca das raízes (MSR), massa dos nódulos secos (MNS), relação massa seca das raízes/massa seca da parte aérea (MSR/MSPA), relação massa dos nódulos secos/número de nódulos (MSN/NN), Nt, P, Pt, Kt, Ca, Cat, Mgt, Mn, Mnt, Fet e Znt. Logo, o tratamento com supertriplo superou na maioria dos parâmetros estudados o fosfato de rocha, devendo por razões de sua disponibilidade residual no solo e sua solubilidade ser adicionado conjuntamente com uma fonte menos reativa de $\mathrm{P}$ nas covas de plantios de espécies arbóreas utilizadas nos programas de recuperação de áreas degradadas.;

- Os tratamentos microbiológicos utilizando rizóbio isolado $(R)$ ou em inoculação conjunta com os fungos micorrízicos $(\mathrm{R}+\mathrm{M})$ foram superiores na grande maioria dos parâmetros estudados em relação aos tratamentos testemunha e micorriza isolada (M). Praticamente não houveram diferenças significativas entre $\mathrm{R}$ e $\mathrm{R}+\mathrm{M}$ e entre Test. e M.; 
- A grande maioria dos ajustes matemáticos para os níveis de fósforo adicionados ao solo de restinga degradado em ambas as espécies tiveram um ajuste linear, não atingindo um ponto de inflexão da curva e consequentemente as plantas responderiam a níveis mais elevados de $P$;

- Os tratamentos FrR, FrRM, FtR e FtRM tiveram mais equações ajustadas do que os restantes dos tratamentos, por apresentarem maior desenvolvimento na maioria dos parâmetros em virtude da fixação biológica do nitrogênio (FBN);

- Os níveis de $\mathrm{P}$ testados não influenciaram a taxa de colonização micorrízica, não apresentando assim efeitos depressivos para a colonização micorrízica;

- As plantas responderam à inoculação com Bradyrhizobium, reforçando a necessidade de inoculação com estirpes previamente selecionadas, principalmente em solos arenosos como os utilizados neste trabalho.

\section{REFERÊNCIAS BIBLIOGRÁFICAS}

1. BRAGA, Roberto. Fundamentos e técnicas de administração financeira. 1 ed. São Paulo: Atlas, 1989.

2. BRIGHAM, E. F. et al. Administração financeira: teoria e prática. São Paulo: Atlas, 2001.

3. BATAGLIA, O. C. et al. Métodos de análise química das plantas. Instituto Agronômico, Campinas, 1983. 48 p. (Boletim 78). 2001. CD-ROM.

4. CARNEIRO, J. G. A. Produção e controle de qualidade de mudas florestais. UFPR/FUPEF/UENF, Viçosa, 1995. 451p.

5. CARVALHO O.O. et al. Perfil Industrial da cerâmica vermelha no Rio Grande do Norte. Natal: Federação das Indústrias do Rio Grande do Norte, 2001. CD-ROM.

6. EMPRESA BRASILEIRA DE PESQUISA AGROPECUÁRIA. Revegetação de solos degradados. Itaguaí, 1992. 9p.

7. EMPRESA BRASILEIRA DE PESQUISA AGROPECUÁRIA. Manual de análises de solos. Brasília, 1989. 179p.

8. FONSECA, F. A. Produção de mudas de Acacia mangium e Mimosa artemisiana utilizando resíduos urbanos como substratos, associados a fungos micorrízicos arbusculares., Seropédica: Embrapa Agrobiologia, 2010. 24 p. (Embrapa Agrobiologia. Boletim de Pesquisa e Desenvolvimento, 67).

9. FRANCO. et al. Uso de leguminosas florestais noduladas e micorrizadas como agentes de recuperação e manutenção da vida do solo: Um modelo tecnológico. In: ESTEVES, F. A. De. Estrutura, funcionamento e manejo de ecossistemas brasileiros. S1p., 1995. P 459-467.

10. GOI, S. R. Nitrogen nutrition of nodulated wood legumes. PhD. Thesis. University of Dundee, Scotland, U.K., 1993.

11. GOI, S. R.; SPRENT, J. I.; JAMES, E. K. \& JACOB-NETO, J. Influence of nitrogen form and concentrations of the nitrogen fixation of Acacia auriculiformis. Symbiossis, V. 14, p.115-122, 1992.

12. GOMES, J. M.; COUTO, L. \& PEREIRA, A. R. Uso de diferentes substratos na produção de mudas de Eucalyptus grandis em tubetes e em bandejas de isopor. Revista Árvore, 9 (1): 58-86, 1985. 
13. HABTE, M. \& SOEDARJO, M. Mycorrhizal inoculation efect in Acacia mangium grown in a acid oxisol amended with gypsum. Journal of plant nutrition. 18 (10): 2059-2073., 1995.

14. HUNGRIA, M. Coleta de nódulos e isolamento de rizóbio. In: HUNGRIA, M. \& ARAÚJO< R. S., eds. Manual de métodos empregados em estudos de microbiologia agrícola. EMBRAPA-SPI, Brasília, 1994. P 45-61.

15. MANJUNATH, A.; BAGYARAJ, D. J. \& GOPALA-GOWDA, H. S. Dual inoculation with VA mycorrhiza and Bradyrhizobium is benefical to Leucaena. Plant and Soil., 78:445-448, 1984.

16. MARTINS, M. A. \& READ, D. J. Efeitos da disrupção do micélio externo de fungos micorrízicosarbusculares sobre o crecimento vegetal. Pesquisa Agropecuária Brasileira. Brasília, v. 32, n. 11, p.1183-1189, 1997.

17. MENDES FILHO, P. F. Efeito da interação Bradyrhizobium. Micorrizas VA e fosfatos no desenvolvimento de mudas de sabiá (Mimosa caesalpiniaefolia Benth. Fortaleza, UFC, 1985. 51 p. (Dissertação de mestrado).

18. OLIVEIRA, E. Efeito do número de esporos de fungos micorrízicos arbusculares no desenvolvimento inicial do sabiá (Mimosa caesalpiniaefolia Benth) em solo ácido. Itaguaí, Universidade Federal Rural do Rio de Janeiro, 1993. 173 p. (Dissertação de mestrado).

19. SUN, J.S.; SIMPSON, R.J \& SANDS, R. Nitrogenase activity of two genotypes of Acacia mangium as affected by phosphorus nutrition. Plant and Soil. 144: 51-58, 1992. A.

20. VASCONCELOS, I. ALMEIDA, R. T. De \& NESS, R. L. L. Competição entre 19 estirpes de Bradyrhizobium sp. Em simbiose com sabiá, Mimosa caesalpiniaefolia Benth. Ciência Agronômica., 17(1):99-103, 1986.

21. VIEIRA, S. \& HOFFMANN, R. Estatística Experimental. Ed. Atlas, São Paulo, 1989. 179p.

22. ZHOU, M.; RHUE, R. D. \& HARRIS, W. G. Phosfhorus Sorption Characteristics of Bh and Bt Horizons from Sandy Coastal Plain Soils. Soil. Sci. Soc. Am. J. 61:1364-1369. 1997. 